10 years ESJ

Special edition

\title{
Tourism Sector in Albania: Post-Pandemic Challenges Require New Mindsets
}

\author{
Loren Lazimi \\ Assistant Lecturer, Faculty of Economy, University of Tirana, Albania
}

Doi: $10.19044 / \mathrm{esj} .2021 . v 17 \mathrm{n} 11 \mathrm{p} 35$

Submitted: 07 December 2020

Accepted: 22 March 2021

Published: 02 April 2021
Copyright 2021 Author(s)

Under Creative Commons BY-NC-ND

4.0 OPEN ACCESS

Cite As:

Lazimi L. (2021). Tourism Sector in Albania: Post-Pandemic Challenges Require New Mindsets. European Scientific Journal, ESJ, 17(11), 35.

https://doi.org/10.19044/esj.2021.v17n11p35

\section{Abstract}

COVID-19 is a pandemic unknown to mankind, which has turned into a global economic risk that will have long-term consequences. Tourism is one of the hardest-hit sectors by this pandemic and will most likely be the last sector to recover once this story is over. There is a great deal of uncertainty as to what will happen in the future, and this depends mainly on external factors such as the release of a vaccine in the medium term, the health situation in the markets of major suppliers, and the psychological approach to long-term travel in segments like leisure-travels, business-travels, and mass events. It is clear that recovery requires coordinated actions by all stakeholders. In this paper, a survey was carried out between August and the beginning of September 2020 on the perceived impact of COVID-19 on the Albania tourism sector. Representatives of hotels and accommodation units interviewed in Albania gave their views on COVID-19's impact on the sector. This paper shows the real situation and its impact on the operations of organizations, financial situation, and potential strategies in overcoming the crisis. This paper also focuses on creating some scenarios from the perception of COVID-19 impact, and it also gave some strategies to overcome the challenges of post pandemic.

Keywords: Tourism, COVID-19, pandemic, GDP, Albania, economy 


\section{Introduction}

In November 2019, Albania was hit by a high magnitude earthquake, which took a toll on physical infrastructure and economic activity, leaving a burden on the budget prior to COVID-19. Although in recent years, the economy have experienced a constant increase in real GDP growth, due to the earthquake and a decrease in energy production caused by a drought, it went from $4.1 \%$ to an estimated $2.2 \%$ in 2019 . On the other hand, unemployment rates have been constantly declining, reaching $12.3 \%$ in 2018 . The situation for youth has been improving (28\% in 2019), as well as long-term unemployment (67.4\% of all unemployment), although their high levels remain a concern. On the other hand, the share of informal workers kept increasing, reaching 37\% in 2018. This situation has led to an outflow of the young and highly skilled from the country, with more than $30 \%$ of the population residing outside of the country. Net FDI had been decreasing at an estimated 7.6\%, after peaking in 2016 due to Trans Adriatic Pipeline and Devoll Hydropower projects. General government debt stood at $66.7 \%$ of GDP.

Given the small size of the Albanian economy, the policy action is considerable and covers many groups affected by the containment measures. In Fall 2019, the projected GDP growth for 2020 in Albania was 3.4\%, while the GDP growth in April 2020 is projected to be -5\%. Hence, the coronavirus pandemic is expected to produce a notable recession of the economy, which heavily relies on trade with and investments from the EU, particularly Italy. Within the domestic market, SMEs and the manufacturing and tourism sectors will be among the most affected. Unemployment may rise and labor market conditions may further deteriorate, given that a notable share of the workforce lives abroad (around $30 \%$ of the population). Amidst the crisis, the European Commission decided to open accession negotiations with Albania.

COVID-19 is expected to have a big impact on the Albanian tourist industry and on the economy as a whole. The World Travel and Tourism Council released its annual report, analyzing figures relating to tourism in Albania during 2019. It found that tourism's contribution to the country's GDP rose by $8.5 \%$ in 2019 , and that tourism contributed $21.2 \%$ of the total economy. It brought some 275.5 billion ALL ( $€ 2.2$ billion) into the country, accounting for $48.2 \%$ of all exports. People working in the tourism sector also accounted for $22 \%$ of the total number of employed individuals in the country. The figure was stated as 254,300 in 2019.

Tourists from North Macedonia accounted the largest number of visitors $(12 \%)$, followed by Greece (9\%), Italy (8\%), Montenegro (6\%), and UK $(3 \%)$. The rest came from a variety of countries across the world. With international borders still closed as the beginning of the tourism season starts, these figures are expected to drop significantly in 2020. Visual Capitalist has 
processed the data and concluded that Albania, along with Montenegro, Croatia, and Greece are the European countries that will be hit hardest. This is due to their economic dependence on tourism. Previously, the International Monetary Fund predicted a decline in the Albanian economy following the impact of COVID-19.

Therefore, the objective of this paper is to:

$\checkmark$ Present the real situation of the tourism sector affected by COVID-19

$\checkmark$ Obtain a survey around the impact of COVID-19 on the Tourism sector

$\checkmark$ Discuss potential scenarios and effective strategy to overcome the effects

\section{Methodology}

Data for this work were collected using a dual approach as described below:

- Materials published from a wide range of sources including, inter alia: academic literature, sector regulators, industry specialists, international organizations such as the OECD and governments abroad.

- To complement the existing conclusions, the paper conducted a perception survey, where representatives of hotels and accommodation units interviewed in Albania gave their perception on the potential impact of COVID-19 on the Albanian tourism sector, including operations and financial performance. Feedback was also obtained from open interviews with management of high level.

\section{Global Tourism Industry \& COVID-19}

Based on this study, we will see an overview of a growing performance of the tourism industry during recent years, before it was hit by COVID-19.

COVID-19 impact on the Albanian Tourism Industry can be seen through tourist arrivals and tourists spending. A similar approach was adopted by the World Tourism Organization (WTO) in the case of the global industry. The qualitative part of the analysis and the perception survey has focused on the hotel sector. According to the WTO, international tourism has experienced a continued expansion in recent years, with standing set-backs from the SARS epidemic (2003) and financial crisis (2009). Historically, the sector has demonstrated its ability to recover from shocks in demand and has acted as a basis for economic recovery in other sectors as well.

Total international tourist arrivals reached 1.5 billion in 2019 . Average year-on-year increase of $4 \%$ is calculated. International tourism receipts reached 1.5 trillion US\$ in 2018 and are estimated at similar levels for 2019. WTO projected that international tourist arrivals in 2020 could 
experience a year-on-year decline in the region from $60 \%$ to $80 \%$. Therefore, this could translate to revenue losses of $910 \mathrm{bn}$ US\$ to $1.2 \mathrm{tn}$ US\$ in export revenues from tourism according to WTO.

\section{International tourist arrivais}

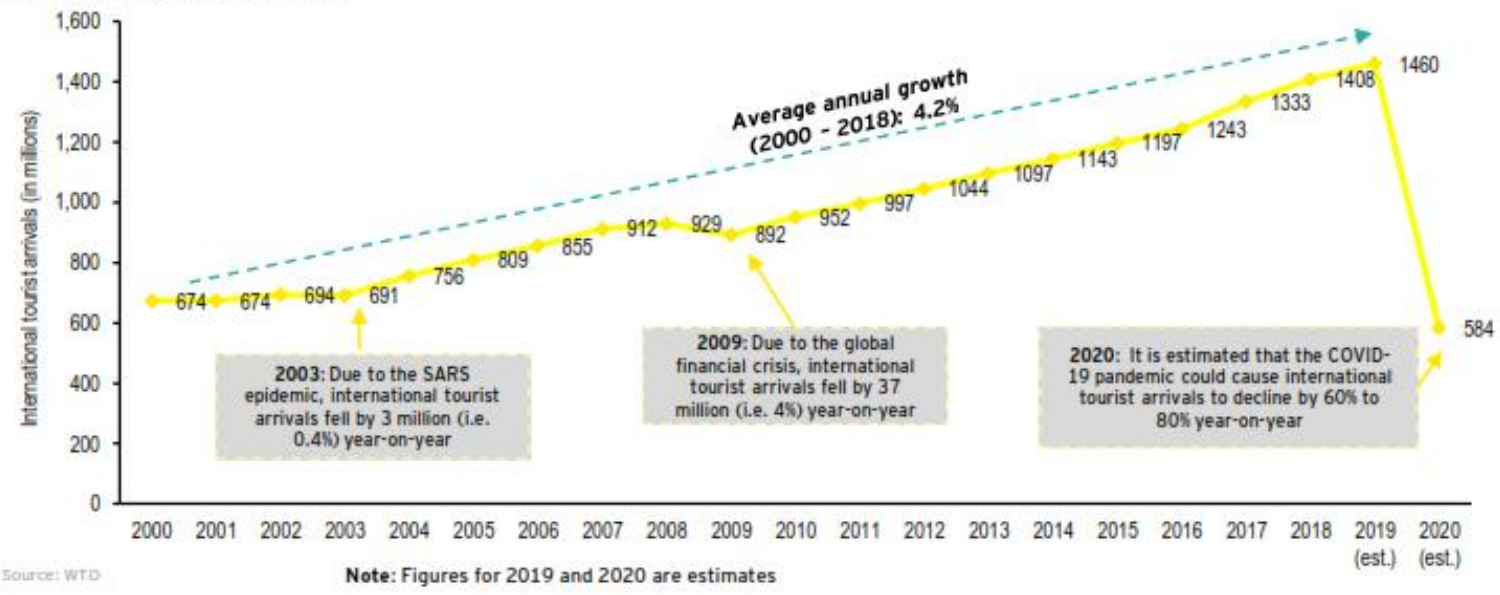

Figure 1.

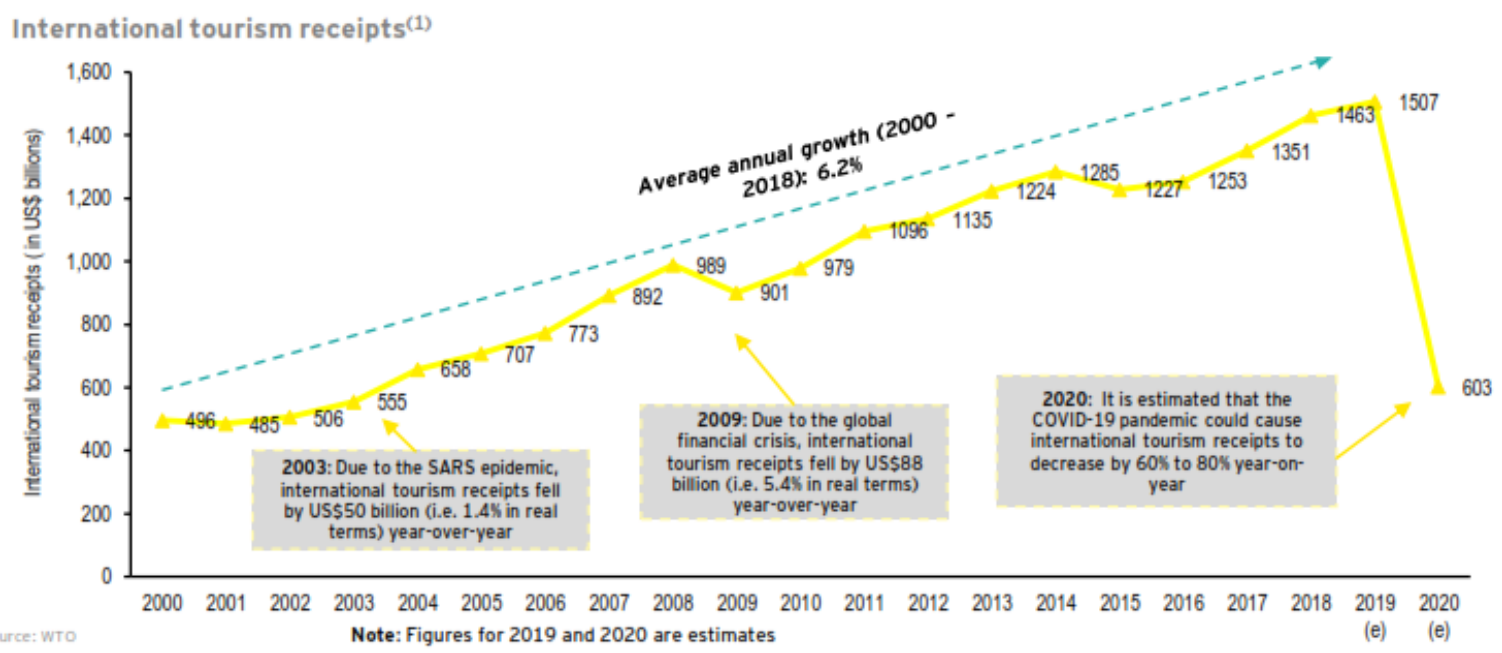

Figure 2.

\section{The Tourism Industry in Albania}

In line with the global tourism sector, the Albanian tourism sector has shown considerable and sustained growth. Tourism is a pillar of the Albanian economy, with substantial direct and indirect contributions towards employment and investment in tourism infrastructure. The increase in the tourism sector was also in line with a general economic growth across all key economic sectors in Albania. Based on the challenges of medium and longterm developments of the Albanian economy, tourism is considered as one of 
the most potential sectors to achieve a higher economic growth and with positive effects on employment growth and real income.

This assessment of the impact of tourism on the Albanian economy is also based on the conclusion of international studies that despite the fluctuations in the world economy, tourism has shown a stable balance to economic and social change. This is reflected in the report of the World Tourism Organization (UNWTO), where in 2017 the number of international tourists increased by $14 \%$ and continued in 2018 by $15 \%$. In 2018 , there were 5.34 million tourist arrivals resulting in direct spending levels of 2.3 billion US\$ into the Albanian economy.

Some studies indicate the sector's contribution at around 15 to $20 \%$ of GDP, including direct, indirect, and induced effects from other sectors such as retail and transport. Thus, this makes this sector one of the key components of the national economy. Despite the legacy of the past, which presents many shortcomings such as seasonal tourism, quality of service, low average costs and substandard staff, Albania's position in the international tourism market has grown and has become more stable.

\section{International tourism, number of arrivals - ALB}

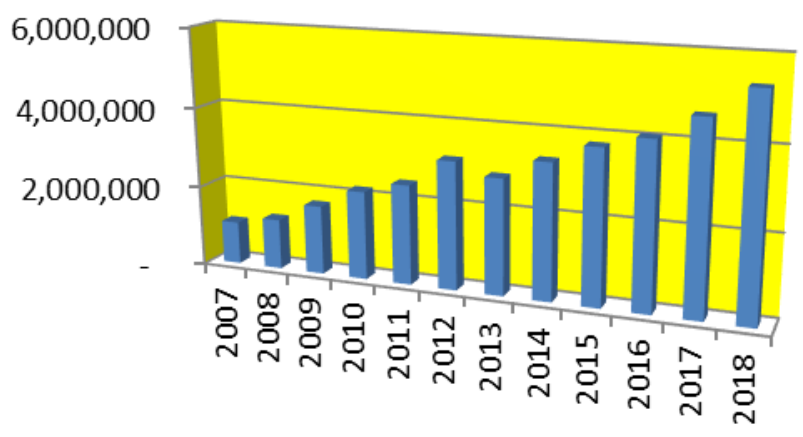

International tourism, number of arrivals

Source: World Bank - World Development Indicators

Figure 3. 


\section{International tourism, receipts (current US\$\$) - ALB}

2,500,000,000

$2,000,000,000$

$1,500,000,000$

$1,000,000,000$

$500,000,000$

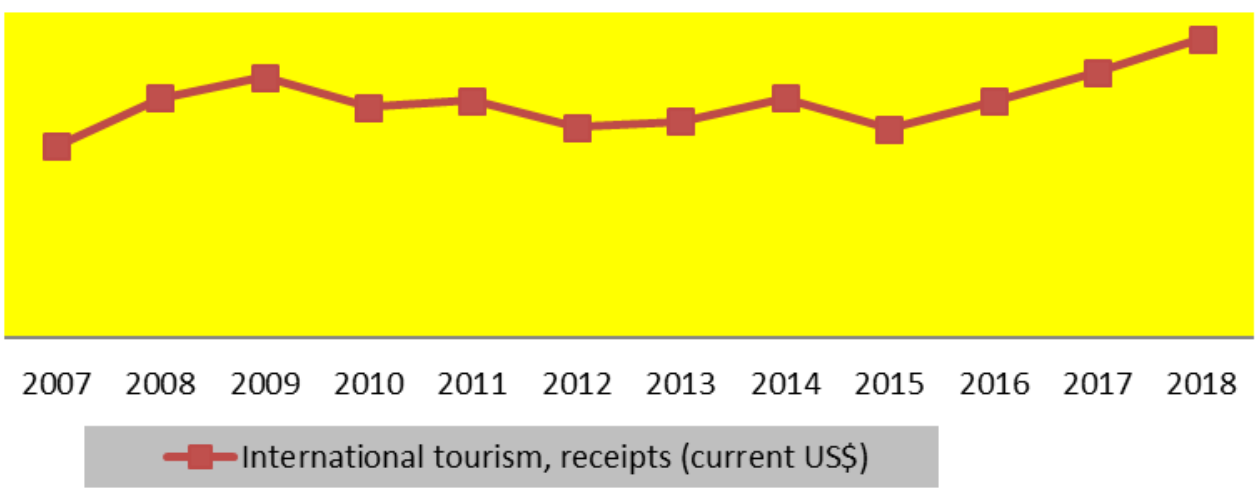

Source: World Bank - World Development Indicators

Figure 4.

\section{Number of persons employed in accommodation and food services - ALB}

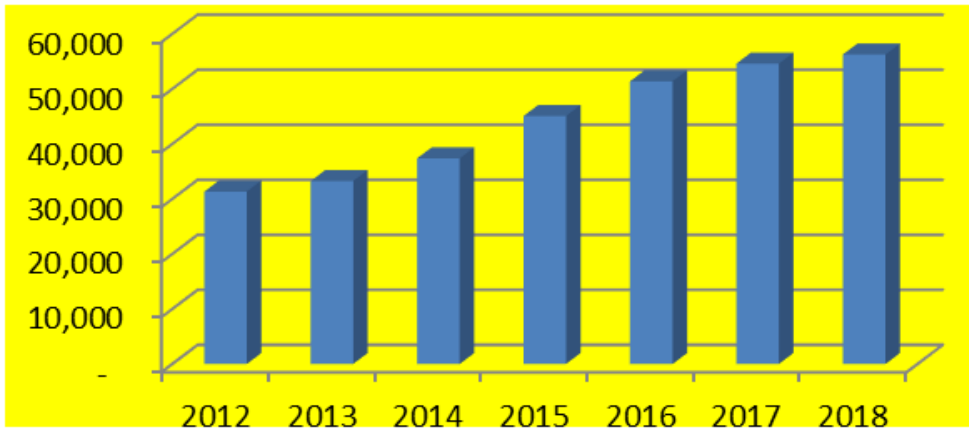

Number of persons employed in accommodation and food services

Source: CEIC - Micro \& Macroeconomic Data

Figure 5.

\section{Tourism Stakeholders and COVID-19 Impact}

The map of stakeholders of the tourism sector in Albania is very diverse and the impact of COVID-19 is very large, which is a fact that makes the time of recovery very unclear. Some of stakeholders are:

$\checkmark$ Hotels (Independent Hotels, large Group Hotels and Guest Houses)

$\checkmark$ Flights and Airport Operators (Airport, Tour Operators Airlines, Oil jet fuel prices)

$\checkmark$ Transfer - Logistics (Tour operators Transfer, Car Rental Operators and other ground transportation)

Below are a list of COVID-19 impact and stakeholder reaction: 


\section{HOTEL}

\section{Impact}

$>$ Significant reduction in revenue due to cancellation of reservations and tourism expenditures

$>$ Management has difficulty planning

$>$ High losses, referring to the fact that hotels are high-risk businesses in which high fixed costs create liquidity difficulties

\section{Reaction}

$>$ Reduction of operating costs, collection of receivables, negotiation of credit terms and postponement of orders

$>$ Postponement of capital investments

$>$ Reducing staff, reducing advertising costs, and increasing costs for health and safety protocols

\section{CUSTOMERS}

\section{Impact}

$>$ Job insecurity and fear of infection impede movement

$>$ Extra costs of movement, such as mandatory tests and quarantine, reduce the desire to travel abroad

\section{Reaction}

$>$ Cancellation of reservation and travel plans

$>$ Reducing the budget for holidays leads to increased pressure for lower prices

$>$ More sensitive requirements on hygiene, social distance, and increasing requirement for the country level of health as a determining factor in the decision to travel

$>$ Online business meeting by employers to save costs and reduce risks of infection

\section{WORKFORCE}

\section{Impact}

$>$ Reducing the salaries of employees and consequently reducing their income, not forgetting the reduction of new recruitments

$>$ Fear of large exposure despite the provision of social distancing or hygiene conditions

$>$ Abnormal work due to children out of schools, quarantines, and social distancing

\section{Reaction}

$>$ Employees seek financial assistance from the government 
$>$ Require from the employer conditions related to hygiene and social distance which is costly

$>$ Employees seek not to work just for fear of infection

\section{SUPPLIERS}

\section{Impact}

$>$ Reducing demand for key hotel supplies (food \& beverage, linen, toiletries, etc.)

$>$ Failure to pay on time from some hotels that have financial difficulties

$>$ Supply interruptions or delays due to movement difficulties

\section{Reaction}

$>$ Reduce costs, including staff redundancies, reduce salaries, and seeking financial assistance from the government

$>$ Change of credit terms, reduction of inventories, etc.

\section{RESTAURANTS, BARS \& SHOPS, TRANSPORT COMPANIES Impact}

$>$ Lack of liquidity

$>$ Reduction in revenues due to restricted movement

\section{Reaction}

$>$ Closure of the activity temporarily or suspension of operations

$>$ Cost-cutting and seeking financial assistance from the government

\section{COVID-19 Impact on Albanian Tourism - Perception Survey}

A survey was carried out between August and the beginning of September 2020 on the potential impact of COVID-19 on the Albania Tourism sector. Representatives of hotels and accommodation units interviewed in Albania gave their views on COVID-19's impact on the sector. This session will show the real situation and the impact on the operations of organizations, financial situation, and potential strategies for overcoming the crisis.

It should be noted that the following answers reflect the perception of the respondents at one point in time. Therefore, we must understand that although several months have passed since the start of the pandemic, it is still unclear how the crisis will proceed and consequently the recovery. We must highlight that changes on COVID-19 scenario makes participants' future predictions more difficult. 


\begin{tabular}{ll} 
Form name & Loren Lazimi Survey \\
\hline Form title & Tourism Perception Survey \\
\hline
\end{tabular}

Number of questions

9

Total number of submissions $\mathbf{3 0}$

1. What effects have booking cancellations for 2020 had on your revenue to date? What is your hotel/industry's financial outlook for this year? Write also a comment.

$\square$ (Question type: Multiple-choice, select one)

\section{Answer}

Big $(70 \%-100 \%)$

Moderate $(40 \%-69.9 \%)$

Low $(0.1 \%-39.9 \%)$

No effect $(0 \%)$

Number of respondents

\section{Amount Percentage}

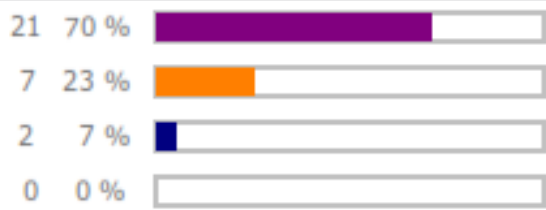

30

2. 2. When do you expect to resume full operations (including the same number of employees if you have fire some of them)? What is your hotel/industry's operational outlook for this year? Write also a comment,

$\square$ (Question type: Multiple-choice, select one)

\begin{tabular}{lrr|} 
Answer & Amount Percentage \\
September - October & 0 & $0 \%$ \\
November - December & 2 & $7 \%$ \\
Next year & 22 & $73 \%$ \\
No idea & 6 & $20 \%$ \\
\hline Number of respondents & 30 & \\
\hline
\end{tabular}

3. 3ow do you think the industry will respond to this crisis? What measures do you intend to adopt to manage the situation? Write also a comment.

$\square$ (Question type: Multiple-choice, select many)

Answer Amount Percentage

Increase the price

$620 \%$

Decrease the price

$2170 \%$ 
Improve service

Rate alting

Tap to domestic market

No idea

Number of respondents

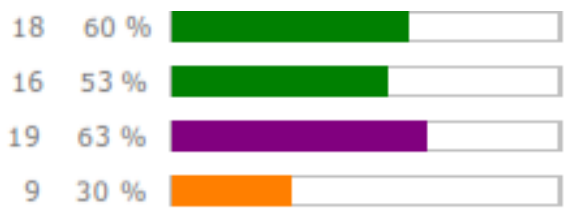

30

4.

4. When will the tourism industry in Albania make a full recovery and return back to 2019 levels? Write also a comment.

$\square$ (Question type: Multiple-choice, select one)

\section{Answer}

0-6 months

7-12 months

Over 1 year

Over 2 year

No idea

Other

Number of respondents

\section{Amount Percentage}

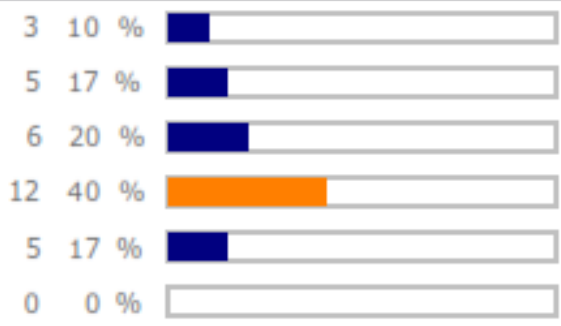

30

5. 5. How is the Covid-19 scenario expected to affect the behavior of prospective guests? Write also a comment.

$\square$ (Question type: Multiple-choice, select many)

\section{Answer}

Demand on social distance spacing,

Prefer venues which are less crowded,

Better cleaning services

Non -acceptance of certain food presentations such as

buffet arrangements

Other

Number of respondents

\section{Amount Percentage}

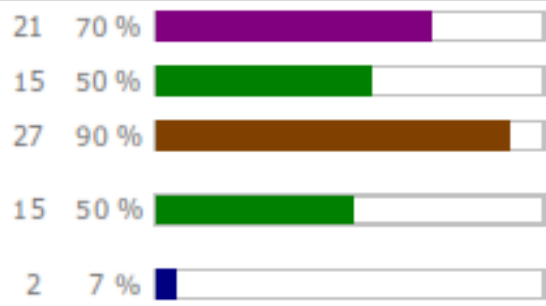

30

6. 6. How does the suspension of your operations impact your suppliers and other service providers? Write also a comment.

$\square$ (Question type: Multiple-choice, select many)

\section{Answer}

Delayed and/or frozen payments to suppliers

Stopped various sub-contracted services.

\section{Amount Percentage}

$$
\begin{array}{ll}
23 & 77 \% \\
18 & 60 \%
\end{array}
$$


Food suppliers who are dependent primarily or solely on hotels are facing difficulties

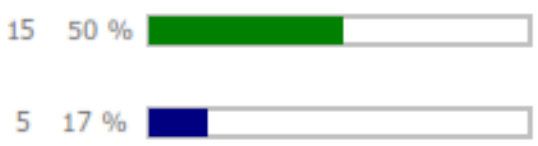

Non essential expenses have been cut. Make e list of kind of expenses.

Number of respondents

7.

7. Are you currently facing any cash flow problems? Will you be seeking liquidity support from/or? Write also a comment.

$\square$ (Question type: Multiple-choice, select one)

\section{Answer}

No

Yes (Bank Overdraft, Employee cuts, Cost reduction, Close the activity)

Number of respondents

\section{Amount Percentage}

$1240 \%$

$1860 \%$

8. 8. How effective are existing Government CovID-19 support measures for the hospitality industry? Write also a comment.

$\boxminus$ (Question type: Multiple-choice, select one)

\begin{tabular}{l|rr}
\hline Answer & Amount Percentage \\
\hline Very effective & 1 & $3 \%$ \\
Moderate & 6 & $20 \%$ \\
\hline Ineffective & 23 & $77 \%$ \\
\hline Number of respondents & 30 & \\
\hline
\end{tabular}

9. 9. How do you plan to overcome the situation created and attract customers when the pandemic ends? Write also a comment.

$\square$ (Question type: Multiple-choice, select many)

Answer

Increase marketing expenses

Make better offers and package

Decrease price

No need of intervention

Other

Number of respondents

\section{Amount Percentage}

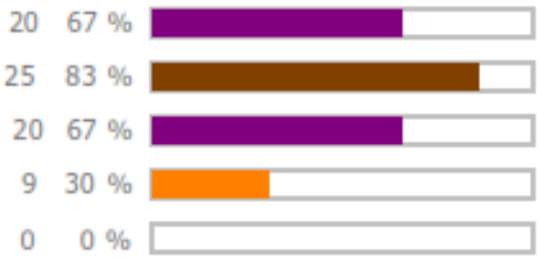

30

Figure 6. 


\section{Additional Feedback}

In the first half of the first quarter of 2020, our hotel recorded booking cancellations of over $70 \%$. We expected revenue growth this year, compared to other years, but the pandemic caused income reduction, which made it difficult to achieve our goal for 2020.

We are already adapted since we took measures for the existing number of guests which now are very few. The measures are from range of offers and price, to the maintenance (cleaning and disinfecting according to the COVID-19 protocol).

We have nothing to do; we cannot deal with the tourist fear to travel.

Hopefully the vaccine is out so people can move freely, but we need to see how far it can go.

The COVID-19 is a humanitarian crisis affecting people's lives. This has a significant impact on the tourism sector, which is critical for many people, places, and businesses. I think this will affect the behavior of all the guests.

We need to work. We are not interested to get support from funds. We need to turn back again, as the situation is totally uncertain.

What did the Government do? Did the Government offer any support? Not at all!
We hope tourism industry will recover next year! This year is totally bankrupted!

Nobody knows and make prognosis; so we may not know what is expected to happen.

All foreigners canceled $100 \%$ for this year. This year we only have Albanians tourists. It seems like a new business venture with Albanian clients especially when you are used to foreigners, which most definitely are easier to deal with, simple, and very respectful towards pretty much everything. This said, the price remains an issue for majority.
We asked for bank loan but all banks have stopped loans for businesses such as hotels and bars.

A plan is a course of action pointing the way to the position we hope to attain. What we need today to achieve our objectives for tomorrow should be explained. The lack of a plan only exacerbates disorientation in an already confusing situation. That's why we are thinking of making better offers and to package to attract customers. 


\section{COVID-19, Tourism - Scenarios and Suggestions for Intervention}

The answers received from our survey indicate the existence of different scenarios according to which the duration of the crisis and recovery at the level of 2019 is unclear. The perceptions of our 60\% respondents show that the recovery can occur over 2 years depending on certain core assumptions.

These include:

- Availability of a COVID-19 vaccine for Albanian people is thought to be valuable later before other countries.

- Insufficient government support for $77 \%$ of the respondents is ineffective.

- Tourism in Albania is dependent on the opening border with Europe; so it depends on the measures that will be taken by European countries.

There is a significant segment ( $17 \%$ of respondents) that has no idea when the recovery will occur because they are confused and unprepared, measures are insufficient, and the situation is not in their hand.

Consequently, this paper identified the following Albanian tourism factors that are expected to influence the sector in the near term.

$>$ Vaccine: In Albania, as in the rest of the world, any implication on the tourism sector depends on finding a vaccine or the necessary medical treatment for COVID-19. Everything else is related to this reality. This is the most important factor for people to be psychologically convinced to travel.

$>$ Domestic Tourism: More and more experts are promoting domestic tourism so that tourism-related businesses can withstand the effects of COVID-19. This is not relevant for Albanian small market and the large hotels. That is why most of the respondents declare a drop in income to the level of $70 \%$ and see the difficult recovery to be realized within the year.

> Passenger Expectations: Passengers will require new hygiene protocols and will also require smaller and smaller accommodation facilities, without too many people and if it is possible to receive noncontact services. Non-contact services referring to the Albanian culture seems impossible, but on the other hand the existence of small accommodation unit can psychologically help the movement for vacation.

$>$ Purchasing Power: Seeing that more and more people are budgeting less for holidays because their incomes are falling, this will lead to small movements in neighboring countries. This favors Albania as 
most of the tourists come from neighboring countries, but it seems impossible in near future as perceived in our survey because people are still scared.

$>$ Competition/New Offers and Packages/Increasing Marketing Budget: Countries will seek to increase marketing budget in order to attract as many tourists as possible, especially in this "new war" that seems to be repositioning tourism-related businesses. This will be costly for businesses in Albania, but they rely on low prices compared to countries in the region. This is the reason $67 \%$ of the respondents see decreasing the price as an alternative, while $83 \%$ of respondents see making better offers and packages as an alternative.

$>$ Governments Support: Governments around the world are increasingly supporting the tourism sector as it is one of the hardest hit sectors. In our survey, we found that $77 \%$ of respondents see Albanian Government support measures ineffective, and this is unacceptable considering the importance of the sector in Albanian economy (15\%$20 \%$ of GDP).

\section{References:}

1. CEIC - Micro \& Macroeconomic Data. https://www.ceicdata.com/en/country/albania

2. Hotel Management, Deloitte, Seven-Rooms share data on guest demands.

https://www.hotelmanagement.net/operate/deloitte-sevenroomsshare-surveys-guest-

demands?mkt_tok=eyJpIjoiTm1Sa01qRmhaV1ZoTWpkbCIsInQiOiJ aTW1OaGVHbURiWUcxNXU4cDIrMEhKZVNEOVFtNzMwOEY 5ZmZPVDhIa3BzZXNsZ1B0akI5Um5melwvNHdFdnJLcFgyVmZn VzhZM1FZSnhlM1h3VCtwSUxKRzRONjJQb2lKVkw1Z1BSS0RL MXIyRTVRU0owQmhSeWVHMG9UQUpEOTZtWmISM1NDS2F 2SG13SzZ3V2FjMnN3PT0ifQ\%3D\%3D\&mrkid=107587487

3. Hotel Management, how a COVID-19 vaccine could affect hotel finances. https://www.hotelmanagement.net/financing/how-a-covid19-vaccine-could-affect-hotel-

finances?mkt_tok=eyJpIjoiTldFeE1tVmtPR05pT1RjeCIsInQiOiJmb E9LdmpzSENMXC9kZU5QNm5tR05IK3pBUkV3SjlkRHZGZXhQ dkdhSTJpbkZnSXhJN1pUN1BmQXpiV05BY1loc29pMllZM0hCVk IRaVR6bVVjQmhNa0NkVklVNXdjQTluV21nOCs3eHNvSjlubzlVa 0J3VHQzREtEVEFFazhuaG1yOVkyR2dHVEoxTDJpOXB6b29TU Dh3PT0ifQ\%3D\%3D\&mrkid=107587487

4. International Monetary Fund (2020). World Economic Outlook (April 2020), Washington D.C. 
https://www.imf.org/external/datamapper/NGDP_RPCH@WEO/OE MDC/ADVEC/WEOWORLD?year=2020

5. OECD (2020). COVID-19 crisis response in South East European economies,

https://read.oecd-ilibrary.org/view/?ref=129_129649-

tclugxbw4j\&title=COVID-19-Crisis-Response-in-South-East-

European-Economies

6. Tourism in figures, Albania 2019, http://www.instat.gov.al/al/publikime/librat/2019/turizmin\%C3\%AB-shifra-2019/

7. World Bank, World Development Indicators http://databank. worldbank.org/data/reports.aspx?source $=2 \&$ series $=\mathrm{S}$ T.INT.ARVL\#

8. World Travel and Tourism Council: Albania 2020 Annual Research https://wttc.org/Research/Economic-

Impact/moduleId/704/itemId/28/controller/DownloadRequest/action/ QuickDownload

9. World Tourism Barometer (2020). Volume 18, May 2020 https://webunwto.s3.eu-west-1.amazonaws.com/s3fs-public/202005/UNWTO_Barom20_02_May.pdf

10. World Tourism Organization. https://data.worldbank.org/indicator/ST.INT.ARVL 